\title{
A arte de se ligar às coisas da cultura: Escola e lei de retorno do capital simbólico
}

\author{
Gilson R. de M. Pereira*
}

\begin{abstract}
RESUMO: Tomando por base a análise realizada por Bourdieu da prática educativa, o estudo examina a especificidade do papel da escola na reprodução social e expõe a lógica da inserção do sistema de ensino no processo de produção e circulação de bens simbólicos. Enfoca as relações que a escola mantém com a lei de retorno do capital simbólico e aborda as determinações tendenciais do capital lingüístico no êxito e no fracasso escolares.
\end{abstract}

Palavras-chave: Escola, reprodução social, capital simbólico, linguagem

A sociologia da educação é um capítulo, e não dos menores, da sociologia do conhecimento e também da sociologia do podersem falar da sociologia das filosofias do poder.

(Bourdieu 1991, p. 117)

Em um inventário dos resultados de duas décadas de estudos sobre currículo, Tomaz Tadeu da Silva constata, entre as lições acumuladas sobre seleção, organização e distribuição do conhecimento escolar, que o conhecimento transmitido na escola é distribuído de forma desigual entre as diferentes classes e os diferentes grupos sociais. Além disso, e ainda entre as lições arroladas, salienta que a escola guarda relações muito estreitas com os processos sociais mais

Professor da Faculdade de Educação da Universidade Regional do Rio Grande do Norte (URRN). 
amplos de acumulação e legitimação da sociedade capitalista. Entre as dúvidas, o autor observa que não sabemos o que constitui conhecimento válido quando tomamos como parâmetro os ideais de construção de uma sociedade democrática, temos dúvida sobre qual a combinação curricular mais adequada à democracia e não sabemos como efetivar mudanças curriculares reais em nossos sistemas de ensino. Sabemos, decerto, quais os fatores que impedem essas mudanças, mas não sabemos como removê-los, como trabalhá-los para realizar as mudanças curriculares necessárias e desejáveis (cf. Silva 1992b, pp. 75-93).

O que é pertinente no momento é a constatação empírica de que o conhecimento escolar é desigualmente distribuído entre as classes e os grupos sociais, muito embora haja, e reconheça-se sua significação moral e sua eficácia política, todo um longo discurso sobre a igualdade de oportunidades escolares. A partir dessa verificação - da distribuição desigual do conhecimento escolar —, observa-se que a escola se encaixa, com uma circularidade quase perfeita, na lei de retorno do capital simbólico: o capital simbólico retorna às mãos dos que já o possuem. Adiante será feita uma análise mais detida dessa lei.

Essa constatação - que data de pesquisas feitas sobretudo na França dos anos 60 - já razoavelmente incorporada ao consenso acadêmico de países europeus e da América do Norte, sendo recente no Brasil, põe em risco a sobrevivência das ingenuidades pedagógicas e, com uma "saudável" chamada ao realismo, torna problemático o otimismo das pedagogias liberais e libertárias. A partir do conhecimento que se dispõe sobre a distribuição seletiva do conhecimento escolar, não nos é permitido ignorar que a escola não tem o poder de redimir pelo conhecimento, não podendo, por conseguinte, ser redentora.

Tudo indica que a prática educativa escolar não pode ser libertadora, não porque os professores não queiram ou adotem pedagogias conservadoras, nem devido a tal ou qual política estatal, mas porque isso está escrito na lógica da inserção da escola no processo de transmissão cultural das sociedades capitalistas. A escola está conformada a uma determinada funcionalidade social e dela talvez só possam ser esperados certos resultados e não outros. Não se trata, portanto, de decidir o papel da escola de acordo com a utilização de uma ou outra pedagogia, a partir da adoção de tal ou qual filosofia da 
educação. A mecânica escolar é indiferente aos dilemas que povoam as mentes dos professores: Prática reprodutivista ou prática libertadora na escola? Dilema que se repete com inquietante tenacidade no cenário educativo brasileiro.

Muito certamente já não há mais dúvida de que o ponto de vista da emancipação, pela escola, das classes populares, é equivocado na essência, pois

\begin{abstract}
a realidade escolar, como parte da realidade social, não se muda nem pela boa vontade dos professores nem pelos decretos do governo. Não basta, como se poderia pensar, que os professores compreendam, amem a classe operária e desejem a salvação escolar de seus filhos para que desapareçam as divisões sociais na escola. Os obstáculos encontrados não têm sua origem na "resistência à mudança dos professores" ou na "força de inércia do sistema": devem-se muito mais fundamentalmente às funções sociais reais do sistema escolar nas sociedades burguesas. (Baudelot 1991, p. 36)
\end{abstract}

A escola é assim, essa é a sua lógica, por necessidade das coisas. Nunca é demais lembrar, alerta Bourdieu: nas coisas sociais e no pensamento do social há necessidades que devem ser trazidas à luz, pela ciência, como forma de se evitar a "cumplicidade imediata" com as coisas sociais e com a representação reificada do social. "O conhecimento científico da necessidade", escreve Bourdieu (1989, p. 105), "encerra a possibilidade de uma ação que tem em vista neutralizá-la, logo, uma liberdade possível - quando o desconhecimento da necessidade implica a forma mais absoluta de reconhecimento".

Em face disso é bastante compreensível o desgosto causado pela ciência ao pôr fim à utopia que projeta para a escola as tendências contestatárias da classe média, ilusão que acomete parte ponderável do professorado, funcionários tão mais ligados ao Estado quanto maior (e mais inconsciente) for a rede de relações que os cinge às coisas de escola, esses elementos reais e imaginários que compõem o universo propriamente escolar. Compreende-se também por que as propostas ingênuas para a escola (Neil, Nidelcoff etc.), as espontaneidades transformadoras, certamente generosas, dos professores e as teorias da conscientização e da resistência terão provavelmente que se conformar à melancolia do fracasso e, talvez, à inocuidade teórica. 


\title{
As implicações da escola na reprodução social
}

O ponto de vista da emancipação, pela escola, das classes populares é equivocado na essência. Se assim o é, o chamado "papel transformador da escola" esbarra numa realidade mais dura, aparentemente mais prosaica e muito mais desafiadora: assim como a escola não é imediatamente responsável pela reprodução social, também não pode ser o motor de transformação da sociedade (cf. Silva 1992b, pp. 85-86).

Essa é uma importante característica reprodutora da escola e fonte de muitos equívocos. Os equívocos nasceram e nascem de uma leitura apressada e superficial das teorias da reprodução social (na falta de outro, vamos conservar o nome "teorias da reprodução". Mas é prudente recusar o caráter de doutrina, de ortodoxia, de conjunto pronto e acabado de métodos, postulados e proposições acerca da transmissão cultural como tem sido às vezes dado pelos críticos a essas teorias). Segundo essa leitura, as teorias da reprodução afirmam "que a educação faz, integralmente, parte da sociedade e a reproduz" (Luckesi 1992, p. 41). Daí, ainda segundo esses leitores, o viés incuravelmente pessimista e desmobilizador dessas teorias.

Em um texto de 1970, cuja lógica vai inspirar o essencial da argumentação destas notas, Bourdieu (1987, p. 295) escreve:

\begin{abstract}
A sociologia da educação configura seu objeto particular quando se constitui como ciência das relações entre a reprodução cultural e a reprodução social, ou seja, no momento em que se esforça por estabelecer a contribuição que o sistema de ensino oferece com vistas à reprodução da estrutura das relações de força e das relações simbólicas entre as classes, contribuindo assim para a reprodução da estrutura da distribuição do capital cultural entre as classes.
\end{abstract}

Em entrevista à professora Menga Lüdke (1991, p. 4), 20 anos depois, Bourdieu ainda trata de elucidar a questão:

Não há nenhuma contradição, nem teórica nem política, no fato de dizer que o sistema escolar contribui (é esta a palavra importante) para reproduzir a estrutura social, e o fato de tentar 
transformá-lo para neutralizar alguns de seus efeitos. Digo exatamente que contribui, em parte que varia segundo os momentos, segundo as sociedades.

Se sustentasse que a escola reproduz a estrutura social, frase tão categórica quanto inexata, Bourdieu estaria, de fato, incorrendo nas oposições e dicotomias que tanto combate: de um lado a reprodução pura e simples, onde a ação dos agentes sociais se volatiza, e de outro a prática pura e simples do sujeito, cuja consciência é absolutizada (cf. Prestes 1993 , p. 16). Tanto num caso como no outro, as mediações estão perdidas. Além disso, a afirmação segundo a qual a escola reproduz a estrutura social desconsidera algo essencial, a saber: a autonomia do campo cultural em relação aos campos político e econômico.

O próprio Althusser, alvo mais constante das críticas, teve o cuidado de sublinhar a palavra "contribui" no seu famoso texto sobre os aparelhos ideológicos de Estado. Referindo-se ao processo de reprodução das relações de produção, Althusser (1974, p. 115) observa: "Os AIE contribuem, como elemento desse processo, para esta reprodução.”

Como se dá, enfim, essa contribuição? - Quais as implicações da escola no processo de reprodução social? Veremos isso ao longo das notas que se seguem, tomando como referência analítica os aportes teóricos de Bourdieu e colaboradores. Antes, devemos observar que o processo geral da reprodução social pode ser visto em uma ampla literatura disseminada em livros e periódicos. Não pretendemos abordar isso aqui, a não ser o estritamente necessário à argumentação. Vamos nos deter muito mais na forma específica da contribuição da escola no processo de reprodução social.

Esquematicamente, a função da escola no sistema de produção e circulação de bens simbólicos é a seguinte:

1. A escola dota os agentes dos esquemas "de percepção, de pensamento e de ação", capazes de torná-los, objetiva e subjetivamente, aptos e dispostos a decifrar os produtos culturais produzidos nas instâncias de produção de bens eruditos. Esses produtos, que são obras "puras, abstratas e esotéricas" (como a ciência, a tecnologia, a música erudita, a língua culta etc.), "são acessíveis apenas aos detentores do manejo prático ou teórico de um código refinado" (Bourdieu 1987, p. 116). Não são, portanto, obras passíveis de uma apreensão imediata. Ou seja, a escola cumpre a função de produção e consagração (pelo diploma) dos 
consumidores e, eventualmente, dos produtores culturais mais adequados - aqueles dotados de habitus secundário (conjunto de disposições e aptidões necessárias à apreensão das obras da cultura culta).

2. A escola legitima e consagra as obras legítimas do passado através de sua incorporação aos programas escolares (transformação em "clássicos").

Assim, segundo esse modelo, a escola ocupa um lugar nas instâncias de reprodução e consagração do campo cultural. Na escola não se produz conhecimento nenhum (a escola produz consumidores de bens culturais e, eventualmente, produtores de conhecimentos), na escola não se inventa nada, ou melhor, inventa-se o já inventado, pensase o já pensado. A cultura propriamente escolar é uma "cultura segunda”, dedicada inteiramente aos imperativos da transposição didática (cf. Forquin 1992).

Uma interpretação complementar é a de Althusser, para quem a cultura escolar é uma "cultura em segundo grau", visando transmitir a um número mais ou menos extenso de indivíduos a "arte de se ligar" às coisas da cultura como meio de inculcação das normas e dos valores socialmente dominantes (cf. Althusser 1976, p. 51).

O passo agora é argumentar como a escola, ao cumprir sua função de reprodução cultural, contribui para a reprodução das estruturas sociais.

Deve-se observar, primeiramente, que o que é reproduzido no campo cultural é a estrutura das relações que todas as classes e todos os grupos sociais mantêm com a cultura dominante. Nessas relações atuam os mecanismos da reprodução cultural. Uma posição de força material inicial, determinada pela posse diferencial de capital econômico, permite que a cultura das classes e dos grupos dominantes seja definida como "a" cultura. Esse arbitrário cultural - "a" cultura: cultura dominante, cultura erudita, cultura culta, alta cultura, uma escolha entre outras que não parece ser uma escolha - é transmutado, pela alquimia das relações de força entre as classes sociais, em capital simbólico - uma espécie de capital que incorpora no agente, como se fosse algo natural nele, os outros capitais; distinção; credibilidade conferida ao agente pelos demais agentes. "O capital simbólico, geralmente chamado prestígio, reputação, fama", escreve Bourdieu (1989, p. 134), "é a forma percebida e reconhecida como legítima das diferentes espécies de capital”. Os possuidores de capital simbólico são dotados de poder simbólico, espé- 
cie de poder quase natural e incessantemente naturalizado, que confere aos seus detentores a legitimidade pela enunciação legítima da palavra. Os indivíduos passam a ser classificados em função da posse ou do déficit de capital simbólico. O capital simbólico, por sua vez, dissimula as relações de força materiais.

Tem-se, portanto, uma força simbólica, reproduzida no campo simbólico, mas nascida de uma força material (determinada pelo diferencial de capital econômico), dissimulando e contribuindo para manter, pela dissimulação, a posse desigual de capital econômico.

A participação da escola em todo o processo que acabamos de descrever, e cuja concisão expositiva devemos a Tomaz Tadeu da Silva (1992a, p. 138), está na distribuição e na classificação do capital cultural com vistas à legitimação. Considerando que os bens culturais da cultura culta, dado que raros e esotéricos, só podem ser apreendidos pelos possuidores dos códigos necessários à decifração desses bens, e considerando que a escola não dota igualmente todos os agentes dos esquemas de pensamento necessários à decodificação dos bens culturais produzidos no campo de produção cultural, a conclusão a que se é levado é que a escola contribui para reproduzir a força simbólica que dissimula a estrutura das relações sociais. Com outras palavras: o sistema de ensino "reproduz um arbitrário cultural do qual ele não é o produtor (reprodução cultural) e cuja reprodução contribui à reprodução das relações entre os grupos ou as classes (reprodução social)" (Bourdieu e Passeron 1992, p. 64). Na seqüência veremos alguns aspectos desse processo.

Escola e capital simbólico: A lei de retorno

A lei de retorno do capital simbólico pode ser, muito sumariamente, expressa da seguinte forma: o capital simbólico incorpora-se no capital simbólico. Esta lei é a manifestação, no plano simbólico, da lei mais geral de acumulação dos capitais. No campo econômico, onde se dá o paradigma da lei geral de acumulação do capital, o embate das forças propriamente econômicas favorece, como se sabe, a concentração do capital nos pólos onde há mais densidade de capital. A funcionalidade das instituições econômicas capitalistas é a de favorecer e impulsionar essa lei mais geral, em meio às contradições resultantes das lutas entre os diversos agentes econômicos. 
Do mesmo modo, no campo cultural há a tendência à concentração de capital cultural nos pólos de maior densidade cultural. As instituições culturais estão conformadas a essa tendência. Assim como as instituições e os agentes econômicos se regulam e são regulados pela tendência de concentração do capital econômico, a escola, enquanto instituição cultural, regula-se e é regulada para a concentração do capital simbólico.

A escola está estruturada para contribuir com a lei de retorno do capital simbólico ao classificar os capitais culturais e selecioná-los com vistas à legitimação. Ao maior volume de capital cultural inicial, propriedade dos agentes que ocupam posições médias e altas no espaço social, a escola agrega o capital propriamente escolar (uma cultura racionalizada), e, posteriormente, procede à legitimação, pelo diploma, concedendo o êxito escolar. Aos capitais culturais deficitários, propriedade dos agentes culturalmente despossuídos e que ocupam os lugares mais baixos no espaço das posições sociais, a escola reserva as difíceis escarpas da acumulação cultural primitiva (para o pequeno grupo dos agentes das classes populares que terão acesso aos postos mais altos da escolarização) ou o fracasso total (evasão e repetência), ou o êxito moderado (saberes práticos, cursos técnicos, ofícios).

A escola distribui desigualmente o capital simbólico entre as classes e os grupos sociais porque a distribuição escolar do capital cultural depende tendencialmente do capital simbólico incorporado pelos agentes antes da escolarização, e a incorporação prévia é função da posição ocupada pelos agentes na topografia social. Neste sentido, o mais rigoroso é dizer que a escola redistribui desigualmente o capital cultural, pois a distribuição que a escola processa depende das distribuições anteriores. E já que "o volume do capital cultural determina as probabilidades agregadas de ganho em todos os jogos em que o capital cultural é eficiente" (Bourdieu 1989, p. 134), compreende-se por que os ganhos escolares não são de modo algum aleatórios.

\footnotetext{
Desta forma o capital cultural que as escolas tomam como um dado age como um filtro altamente eficaz nos processos reprodutivos de uma sociedade hierárquica. O rendimento deficiente de grupos diferentes do dominante numa sociedade, portanto, não é algo inerente à diferença cultural per se, mas é, exatamente na mesma medida que o êxito para os grupos dominantes, um artifício da forma pela qual as escolas operam. (Harker 1990, p. 80)
} 


\section{Escolarização e capital lingüístico}

Detalhemos um pouco mais a questão da distribuição desigual do capital simbólico, que condiciona tendencialmente o êxito e o fracasso escolares, tomando como motivo a linguagem. Como se sabe, a relação pedagógica é uma relação de comunicação por excelência (meIhor dizendo: é uma relação de força simbólica), sendo o capital lingüístico dos falantes um fator determinante na eficácia dessa relação. Digamos que o contrato pedagógico seja enormemente obstaculizado pelas disfunções comunicacionais e que o rendimento do trabalho pedagógico seja diretamente proporcional à performance informativa da comunicação. Digamos que a comunicação pedagógica, por sua vez, seja realizada num código cifrado e complexo - a linguagem propriamente escolar - mais ou menos distante dos códigos manejados no cotidiano (não nos esqueçamos de que o conteúdo da escola é a cultura erudita didaticamente transposta, e não o senso comum e os saberes populares). Em função disso, só os estudantes das classes e dos grupos sociais que ocupam posições médias e altas no espaço das posições sociais, e os estudantes fortemente selecionados das classes populares (os sobreviventes), conseguem atender às exigências lingüísticas da escola. Isso se dá porque "a aptidão à decifração e à manipulação de estruturas complexas, quer elas sejam lógicas ou estéticas, depende em certa parte da complexidade da língua transmitida pela família" (Bourdieu e Passeron 1992, p. 83).

A conclusão a que se chega é que a mortalidade escolar aumenta nas classes e nos grupos sociais cuja linguagem familiar se afasta da linguagem escolar. Os agentes das classes populares têm enorme dificuldade, na maioria das vezes insuperável, em decodificar a língua escolar, tanto oral quanto escrita, pois tendem a usar um "código restrito" de linguagem. Isto é, suas opções lingüísticas, sendo fortemente limitadas, inabilita-os, de saída, à competição num meio onde a competência lingüística é a moeda corrente, ao contrário dos agentes das classes e dos grupos sociais dominantes, que, por tenderem a usar um "código elaborado" de linguagem, se encontram perfeitamente à vontade no meio escolar (cf. Morrish 1983, pp. 151-154).

Nos termos de Bourdieu (1983, pp. 156-183), tudo isso pode ser dito da seguinte forma: são baixas as chances objetivas de acesso dos agentes das classes populares aos instrumentos de produção da com- 
petência legítima em matéria de comunicação, pois os seus habitus (disposições permanentes de pensar e agir) lingüísticos, que são dimensões do habitus de classe, expressão da posição ocupada na topografia social, não os predispõem ao manejo prático dos códigos intelectuais necessários à decodificação de bens culturais complexos (ciência, artes, letras etc.). Logo, tais agentes têm probabilidades reduzidas de obtenção de lucro lingüístico, isto é, têm fracas expectativas de receber preços mais ou menos elevados pelos seus discursos (reduzidas chances de legitimidade discursiva). O resultado é o fracasso tendencial na relação pedagógico-escolar, pois esta relação, enquanto relação de força simbólica, visa à seletividade com base na maximização do desempenho comunicativo.

O baixo rendimento escolar dos alunos das classes populares não deve, por conseguinte, ser creditado nem à falta de inteligência nem ao desinteresse, assim como o satisfatório rendimento dos alunos das classes médias e altas não deve, via de regra, ser creditado a dotes intelectuais ou ao interesse. Essas explicações tão naturais e naturalizantes do professor médio, que procura se proteger e proteger a escola, instituição que o protege, passam ao largo da função de seletividade cognitiva que a escola desempenha na sociedade.

A forte mágica social da escola, tão eficaz que encontra uma verdadeira plêiade de ideólogos capazes das mais barulhentas guerras na defesa e na valorização da escola pública (como se o fato de ser pública ou privada mudasse em algo na coisa), reside na dissimulação e na legitimação das sanções e seletividades escolares.

Capital lingüístico (herdado da família), rendimento escolar e escolha vocacional estão inter-relacionados na lógica das estratégias culturais das classes sociais. $\mathrm{Na}$ aparência tudo se passa como se todos os agentes sociais, independente de suas posições sociais, fizessem naturalmente suas opções escolares e profissionais. Do ponto de vista da percepção imediata das coisas, tudo se passa como se o filho do pedreiro escolhesse livremente ser pedreiro, e todo o seu investimento escolar fosse guiado por essa escolha, e o filho do médico, por vocação e manifestação livre de sua vontade, escolhesse ser médico ou advogado, conduzindo assim seus investimentos escolares para essa preferência. É necessário romper com toda essa percepção imediata do social e mostrar que nas escolhas escolares aparentemente mais livres há estratégias culturais de classes que condicionam as opções mais subjetivas dos agentes (cf. Nogueira 1991). É possível mostrar, com rigor e exatidão, que 
as vocações e as profissões não são escolhas assim tão livres, e que os títulos escolares não são aleatoriamente distribuídos. Mas é necessário se precaver contra a tentação de interpretar déficit e superávit lingüísticos como propriedades substanciais das classes e dos grupos sociais, como essências biológicas ou culturais que impõem mecanicamente aos indivíduos específicos modos de agir e pensar. O capital lingüístico é um conceito relacional: enuncia as disposições lingüísticas construídas pelas classes e pelos grupos sociais em tempo e espaço determinados do mercado de bens simbólicos (cf. Bourdieu 1996, pp. 16-18).

De modo que aqui, outra vez, vemos a escola inserida na lei de retorno do capital simbólico: a maior probabilidade de êxito escolar está reservada aos alunos sintonizados com os códigos lingüísticos da escola. Os alunos mais ricos em capital lingüístico são os mais prováveis merecedores da consagração escolar. A estes a honra ao mérito, os diplomas das melhores universidades (garantia para os melhores postos de emprego), o prestígio, o reconhecimento, enfim, o capital simbólico se incorporando ao capital simbólico. Aos outros, aos que têm déficit em capital lingüístico, a repetência, a evasão, os diplomas de cursos noturnos "mal tirados", enfim, essas marcas sociais que contribuem para reproduzir as posições dominadas do campo social.

\section{Considerações finais}

Tudo o que foi escrito até aqui permanece para nós entre parênteses se não for posto à prova no confronto com realidades específicas (cf. Rockwell 1990). Trata-se de tomar esse poderoso arsenal conceitual, que não é exclusivo, e relê-lo com o propósito de conhecer no detalhe como se dão os processos reprodutivos na sociedade brasileira e qual a contribuição do sistema de ensino para a eficácia desses processos. A dificuldade reside precisamente em agarrar, na expressão de Bourdieu, "o invariante, a estrutura, na variante observada": isto é, agarrar "a particularidade de uma realidade empírica, historicamente situada e datada, para construí-la, porém, como 'caso particular do possível', conforme a expressão de Gaston Bachelard, isto é, como uma figura em um universo de configurações possíveis" (Bourdieu 1996, p. 15). Não se trata de afirmar abstratamente se as teorias da reprodução estão certas ou não - esse tem sido o equívoco mais freqüente - ou de afir- 
mar que as teorias da reprodução são a priori inadequadas ao nosso contexto latino-americano ou terceiro-mundista, dado que construídas nas realidades européia e norte-americana, mas sim de submetê-las à prova empírica, de, como salienta Grignon, "confrontar a problemática da reprodução com a diversidade de situações e territórios escolares sem temer aventurar-se em direção às instituições que ocupam as posições mais baixas ou mais 'excêntricas' na hierarquia do sistema de ensino, tal e como sucede com a escola primária ou com o ensino técnico" (Varela 1990, p. 186).

Esse é o problema e o desafio. Devemos reconhecer que temos feito poucas pesquisas estatísticas na área da educação. Não conhecemos, ou conhecemos muito pouco, os detalhes das estratégias culturais das classes sociais no Brasil. O que sabemos das disposições culturais dos professores? Qual o impacto da inflação de credenciais na sociedade brasileira? Qual o impacto no sistema universitário da irrupção de novas universidades privadas, dotadas de competitividade e de projetos próprios e singulares? Qual o perfil da clientela dos cursos escolares informais? Qual a qualidade do ensino técnico, público e privado, ministrado no Brasil? O que sabemos da distribuição social dos investimentos escolares? Em suma, temos feito pesquisas destinadas a observar as tendências da reprodução social? Muito pouco. Sem querer de modo algum desqualificar o debate teórico, devemos reconhecer que temos a mania, na pesquisa acadêmica, de fazer trabalhos doutrinários, de ruminar velhas polêmicas, de bater a frio em oposições já superadas. Manejamos uma reduzida massa de informações porque trabalhar em educação com dados empíricos, números e tabelas é ser candidato a receber a considerada nada honrosa classificação de "positivista".

Não há dúvida de que até agora o livre jogo das forças simbólicas na universidade brasileira tem sido desfavorável às teorias da reprodução. Mas depois de recentes trabalhos de pesquisadores brasileiros, como os já citados, e dos estudos epistemológicos de Veiga Neto (1992; 1993), além de outros trabalhos importantes, tais como os de Martins (1987), Catani (1994), Castro (1995) e Rocha (1995), tomando apenas uma pequena amostra da produção na área educacional, e da tradução e divulgação entre nós de importantes pesquisas realizadas na Europa e nos Estados Unidos, espera-se que as teorias da reprodução sejam, sem propósitos exclusivistas, retiradas do ostracismo no qual foram injustificadamente postas. 
How to join cultural contents:

The school and the symbolic capital revenue law

ABSTRACT: Based on the analysis realised by Bourdieu of the educational practice, the study examines the specificity of the school paper in social reproduction and explores the logic of the introduction of the teaching system in the production process and circulation of symbolic possessions. It shows the relationships that the school maintains with the law of return of the symbolic capital and broaches the determinations of the linguistic capital in the success and failure in schools.

\section{Referências bibliográficas}

ALTHUSSER, Louis. Ideologia e aparelhos ideológicos do Estado. Notas para uma investigação. Lisboa, Editorial Presença, 1974.

Filosofia e filosofia espontânea dos cientistas. Lisboa, Editorial Presença,1976.

BAUDELOT, Christian. “A sociologia da educação: Para quê?” In: Teoria \& Educação no 3. Porto Alegre, 1991, pp. 29-42.

BOURDIEU, Pierre. Pierre Bourdieu: Sociologia. Organização de Renato Ortiz. São Paulo, Ática, 1983 (Grandes cientistas sociais 39).

A economia das trocas simbólicas. Introdução, seleção e organização de Sergio Miceli. $3^{a}$ ed., São Paulo, Perspectiva, 1987.

O poder simbólico. Lisboa, Difel, 1989.

"Estruturas sociais e estruturas mentais". In: Teoria \& Educação $\mathrm{n}^{\circ}$ 3. Porto Alegre,1991, pp. 113-119.

Razões práticas. Sobre a teoria da ação. Campinas, Papirus, 1996.

BOURDIEU, Pierre e PASSERON, Jean Claude. A reprodução. Elementos para uma teoria do sistema de ensino. $3^{\mathrm{a}}$ ed., Rio de Janeiro, Francisco Alves, 1992.

CASTRO, Magali. "Contribuições da sociologia clássica e contemporânea para a análise das relações de poder na escola: Um es- 
tudo do poder em Weber e em Bourdieu". In: Educação \& Sociedade № 50. Campinas, abr. 1995, pp. 105-143.

CATANI, Denice B. "Memória e biografia: 'O poder do relato e o relato do poder' na história da educação". Trabalho apresentado na $17^{\mathrm{a}}$ Reunião Anual da Anped. Caxambu, Minas Gerais, 1994. In: VV. AA. Pesquisa histórica: Retratos da educação no Brasil. Rio de Janeiro, UERJ, s.d., pp. 73-80.

FORQUIN, Jean-Claude. "Saberes escolares, imperativos didáticos e dinâmicas sociais". In: Teoria \& Educação № 5. Porto Alegre, 1992, pp. 28-49.

HARKER, Richard H. "Reprodução, habitus e educação". In: Teoria \& Educação oㅜ 1. Porto Alegre, 1990, pp. 79-92.

LUCKESI, Cipriano C. Filosofia da educação. $4^{\mathrm{a}}$ reimpressão, São Paulo, Cortez, 1992.

MARTINS, Carlos B. "Estrutura e ator: A teoria da prática em Bourdieu". Educação \& Sociedade № 27. 1987, pp. 33-46.

MORRISH, Ivor. Sociologia da educação. $4^{\mathrm{a}}$ ed. Rio de Janeiro, Zahar, 1983.

NOGUEIRA, Maria Alice. "Trajetórias escolares, estratégias culturais e classes sociais. Notas em vista da construção do objeto de pesquisa". In: Teoria \& Educação nº 3. Porto Alegre, 1991, pp. 89112.

PRESTES, Nadja Mara H. "Abordagem sociológica do sujeito epistêmico". In: Educação e Realidade no 2. Porto Alegre, jul./dez. 1993, vol. 18, pp. 11-19.

ROCHA, Francisco J. Pimenta. "Vestibular: Cultura e tragédia". In: Educação \& Sociedade № 50. Campinas, abr. 1995, pp. 15-43.

ROCKWELL, Elsie. "Como observar a reprodução". In: Teoria \& Educação no 1. Porto Alegre, 1990, pp. 65-78.

SILVA, Tomaz T. "A dialética da interioridade e da exterioridade em Bernstein e em Bourdieu". In: Teoria \& Educação nํ⒌ Porto Alegre, 1992a, pp. 133-148.

O que produz e o que reproduz em educação. Porto Alegre, Artes Médicas, 1992b. 
VARELA, J. "Para além da reprodução - Entrevista com Claude Grignon". In: Teoria \& Educação n ${ }^{0}$ 1. Porto Alegre, 1990, pp. 180-190.

VEIGA NETO, Alfredo José. "A ciência em Kuhn e a sociologia de Bourdieu: Implicações para a análise da educação científica". In: Educação e Realidade $\mathrm{n}^{\circ}$ 1. Porto Alegre, jan./jun. 1992, vol. 17.

"A teoria da ciência em Kuhn e a sociologia de Bourdieu: As diferenças". In: Educação e Realidade nํ⒉ Porto Alegre, jun./dez. 1993, vol. 18. 